\title{
Reactions of 1,3-diazabuta-1,3-dienes with ketenes: how crucial are the steric factors/conformational preferences in influencing reaction pathways?
}

\author{
Alka Marwaha, Amit Anand, R. Senthil Kumar, and M. P. Mahajan* \\ Department of Pharmaceutical Sciences, Guru Nanak Dev University, \\ Amritsar-143 005, Punjab, India \\ E-mail: mohinderpmahajan@angelfire.com
}

\section{Dedicated to the honour of Professor S. V. Kessar, a valued mentor, on the occasion of his $70^{\text {th }}$ birthday}

(received 12 Apr 02; accepted 19 Jul 02; published on the web 27 Jul 02)

\begin{abstract}
The [4+2] cycloaddition reactions of 2-methylthio substituted 1,3-diazabuta-1,3-dienes with monophenyl and diphenyl ketenes and the reliance of the cycloaddition pathways on the conformational preferences of 1,3-diazabuta-1,3-dienes are described.
\end{abstract}

Keywords: 1,3-Diazabuta-1,3-dienes, dihydropyrimidinones, azetidinones, conformational preferences, $a b$ initio and DFT calculations

\section{Introduction}

Ketenes have received extensive consideration owing to their ability to selectively participate as facile $2 \pi$ components in the commonly encountered [2+2] cycloaddition reactions with alkenes ${ }^{1}$ as well as carbon-nitrogen double bonds of imines ${ }^{2}$ and azadienes. ${ }^{3}$ It offers an entrenched route to the synthesis of four-membered carbocyclic ${ }^{3}$ and heterocyclic systems including imperative intermediates for various antibiotics and natural products. ${ }^{4}$

The cycloadditions of 1,3-diazabuta-1,3-dienes with ketenes have been reported to form [4+2] or [2+2] cycloadducts ${ }^{5,6}$ and their formation have purely been explicated on steric grounds. ${ }^{5}$ It was observed that the reactions of 1,3-diazabuta-1,3-dienes (1a-1c) with diphenyl ketene led exclusively to the formation of azetidinones $\mathbf{3}$ and the formation of [4+2] cycloadducts were thought to be inhibited by the proximity of bulky substituents in the corresponding six-membered ring 4. Similarly, the preferred formation of pyrimidinone $\mathbf{4}$ and exclusion of $\mathbf{3}$ in reactions of $\mathbf{1 d}$ with diphenylketene was also attributed to steric reasons ${ }^{5}$ (Scheme 1). These reactions were believed to proceed through a stepwise mechanism involving a 
zwitterionic intermediate 2 and the theoretical calculations suggested that the formation of azetidinone is a kinetically governed process and is much higher in energy than the corresponding [4+2] cycloadduct. $^{5 \mathrm{c}, 5 \mathrm{~d}}$ Earlier disclosures from our laboratory have shown that the reactions of polarized 1,3-diazabuta-1,3-dienes (1b,1e-1f) with monosubstituted ketenes resulted exclusively in the formation of [4+2] cycloadducts $^{6}$ and a number of speculative mechanistic possibilities were invoked to explain their formation. ${ }^{6 \mathrm{~d}}$

Recently, it has been reported that the size of substituents at $\mathrm{N}-1$ plays a significant role in controlling the periselectivity observed in electrocyclisation of the zwitterionic intermediate 2 and it has been experimentally established that the reactions of 1,3-diazabuta-1,3-dienes 1 with ketenes involve reversible and irreversible formation of azetidinones $\mathbf{3}$ and pyrimidinones $\mathbf{4}$, respectively. ${ }^{5 \mathrm{~d}}$ For example, the reactions of 1-p-tolyl-2,4-diphenyl-1,3-diazabuta-1,3-diene $\mathbf{1 g}$ with ketenes led to the peri-/stereoselective formation of pyrimidinones $\mathbf{4}$, while the reactions of 1-benzyl-2,4-diphenyl-1,3-diazabuta-1,3-diene $\mathbf{1 h}$ with ketenes resulted in the isolation of corresponding azetidinones 3 . On the basis of calculated potential energies it has been shown that in the former case, the pyrimidinones $\mathbf{4 g}$ are more stable than the hypothetical azetidinones 3g, with two phenyl substituents in vicinal positions ( $\mathrm{N}-1$ and $\mathrm{C}-4$ ), while in the latter case, azetidinones $\mathbf{3 h}$ are relatively more stable and easily isolable because $\mathrm{N}-1$ phenyl is moved away from the $\beta$-lactam ring by the insertion of the methylenic group. ${ }^{5 \mathrm{~d}}$ In view of the arguments presented above it was felt that the [2+2] cycloaddition observed in reactions of $\mathbf{1 b}$ with diphenylketene may possibly be altered to a [4+2] cycloaddition by carrying out reactions with 1,3-diazabutadienes having bulkier N-1 substituents. Such 1,3-diazabutadienes (1i and $\mathbf{1 j}$ ), ${ }^{7}$ having o-tolyl and 1-naphthyl substituents at $\mathrm{N}-1$, have been prepared by the usual procedure and their reactions with monophenyl or diphenylketene have been found to follow the envisaged $[4+2]$ route leading to the synthesis of corresponding pyrimidinones $\mathbf{4 i}$ and $\mathbf{4 j}$. The formation of pyrimidinone 4 in these cases is possibly preferred due to the enhanced steric interaction between $\mathrm{N}-1$ aryl (o-tolyl or 1-naphthyl) and vicinal C-4 phenyl substituent in the corresponding hypothetical azetidinone $3 \mathbf{i}$ and $3 \mathbf{j}^{7}$ (Scheme 1).

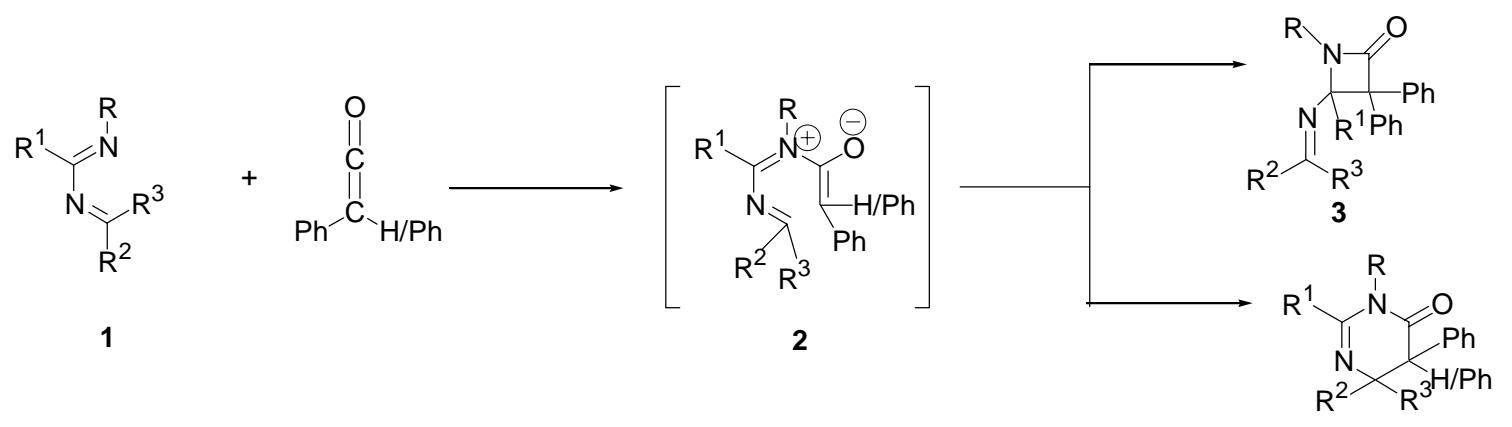

\section{Scheme 1}


However, in a number of the reported reactions of 1,3-diazabuta-1,3-dienes with ketenes, the observed cycloaddition mode appears to be at variance with the expectations on steric grounds. For example, the reactions of diazadienes 1e with diphenylketene and $\mathbf{1 f}$ with phthalimidoketene have been observed to follow a [4+2] cycloaddition route leading to the formation of pyrimidinones $\mathbf{4 e}$ and $\mathbf{4 f}$, respectively, while the reaction of $\mathbf{1 b}$ with diphenylketene led to the isolation of azetidinone $\mathbf{3 b}$ (Scheme 2). ${ }^{6 \mathrm{~d}}$

Table 1. The different products formed from the variously substituted 1,3-diazabuta-1,3dienes and ketenes and the yields of the reactions

\begin{tabular}{|c|c|c|c|c|c|c|c|}
\hline \multirow[t]{2}{*}{ Structures } & \multicolumn{4}{|c|}{ Substituents } & \multirow{2}{*}{$\begin{array}{c}\text { Ketene } \\
\mathrm{R}^{4} \\
\end{array}$} & \multirow{2}{*}{$\begin{array}{l}\text { Product } \\
\text { formed }\end{array}$} & \multirow[t]{2}{*}{ Yield } \\
\hline & $\mathrm{R}$ & $\mathrm{R}^{1}$ & $\mathrm{R}^{2}$ & $\mathrm{R}^{3}$ & & & \\
\hline $\mathbf{a}$ & $\mathrm{Me}$ & $\mathrm{Ph}$ & $\mathrm{Ph}$ & $\mathrm{Ph}$ & $\mathrm{Ph}$ & За & $82 \%$ \\
\hline \multirow[t]{2}{*}{$\mathbf{b}$} & $\mathrm{Ar}$ & $\mathrm{Ph}$ & $\mathrm{NMe}_{2}$ & $\mathrm{H}$ & $\mathrm{H}$ & $4 b$ & $92 \%$ \\
\hline & & & & & $\mathrm{Ph}$ & $3 b$ & \\
\hline C & t-But & $\mathrm{Ph}$ & t-But & $\mathrm{H}$ & $\mathrm{Ph}$ & $3 c$ & \\
\hline d & p-OMe & t-But & t-But & $\mathrm{H}$ & $\mathrm{Ph}$ & $4 d$ & \\
\hline $\mathbf{e}$ & $\mathrm{Ar}$ & SMe & $\mathrm{NMe}_{2}$ & $\mathrm{H}$ & $\mathrm{H}$ & $4 \mathrm{e}$ & $95 \%$ \\
\hline $\mathbf{f}$ & $\mathrm{Ar}$ & $\mathrm{Ph}$ & $\begin{array}{c}\text { Sec. } \\
\text { amino }\end{array}$ & SMe & $\mathrm{H}$ & $4 \mathrm{f}$ & \\
\hline \multirow[t]{2}{*}{ g } & $\mathrm{Ar}$ & $\mathrm{Ph}$ & $\mathrm{H}$ & $\mathrm{Ph}$ & $\mathrm{H}$ & $4 g$ & $66 \%$ \\
\hline & & & & & $\mathrm{Ph}$ & $4 g$ & $75 \%$ \\
\hline \multirow[t]{2}{*}{$\mathbf{h}$} & $\mathrm{Bz}$ & $\mathrm{Ph}$ & $\mathrm{H}$ & $\mathrm{Ph}$ & $\mathrm{H}$ & $3 \mathrm{~h}$ & $57 \%$ \\
\hline & & & & & $\mathrm{Ph}$ & $3 \mathrm{~h}$ & $64 \%$ \\
\hline \multirow[t]{2}{*}{$\mathbf{i}$} & 1-Naphthyl & $\mathrm{Ph}$ & $\mathrm{NMe}_{2}$ & $\mathrm{H}$ & $\mathrm{H}$ & $4 \mathrm{i}$ & $84 \%$ \\
\hline & & & & & $\mathrm{Ph}$ & $4 i$ & $85 \%$ \\
\hline \multirow[t]{2}{*}{$\mathbf{j}$} & o-Tolyl & $\mathrm{Ph}$ & $\mathrm{NMe}_{2}$ & $\mathrm{H}$ & $\mathrm{H}$ & $4 j$ & $90 \%$ \\
\hline & & & & & $\mathrm{Ph}$ & $4 j$ & $81 \%$ \\
\hline
\end{tabular}

\section{Results and Discussion}

In order to have a deeper insight into the mechanistic aspects and to ascertain the significance of steric factors in dictating the course of 1,3-diazabuta-1,3-diene-ketene cycloadditions, it was thought worthwhile to examine these reactions with 1,3-diazabuta-1,3-dienes bearing bulky phenyl groups at C-4 and a methylthio group at C-2 position. The desired 2-methylthio-1phenyl/benzyl-4,4'-diphenyl-1,3-diazabuta-1,3-dienes (1k-1l) have been obtained by the treatment of diphenylmethanimine with phenyl/benzylisothiocyanate, methylation of the thioamide so obtained with methyl iodide and basification of the resulting hydroiodide salt with 
triethylamine. The treatment of $\mathbf{1 k}$ with phenylketene, generated insitu from phenylacetyl chloride and triethylamine, has been found to result in the formation of previously unknown [4+2] cycloadduct which has been characterized as 2-methylthio-3,5,6,6'-tetraphenyl-3,4,5,6tetrahydropyrimidin-4-one (5a) on the basis of analytical and spectral evidences. Its IR (KBr) showed a strong absorption at $1708 \mathrm{~cm}^{-1}$ characteristic of a six-membered amide carbonyl group. Its ${ }^{1} \mathrm{H}$ NMR and ${ }^{13} \mathrm{C}$ NMR signals are also in agreement with the assigned structure. Clearly, the pyrimidinone 5a having three phenyl groups in close proximity to each other must encounter severe steric interactions as compared to the alternative azetidinone 6a. Further, the reaction of 1k with diphenylketene, generated insitu from diphenylacetyl chloride and triethylamine, also resulted in the exclusive formation of [4+2] cycloadduct which was characterized as pyrimidinone $\mathbf{5 b}$.

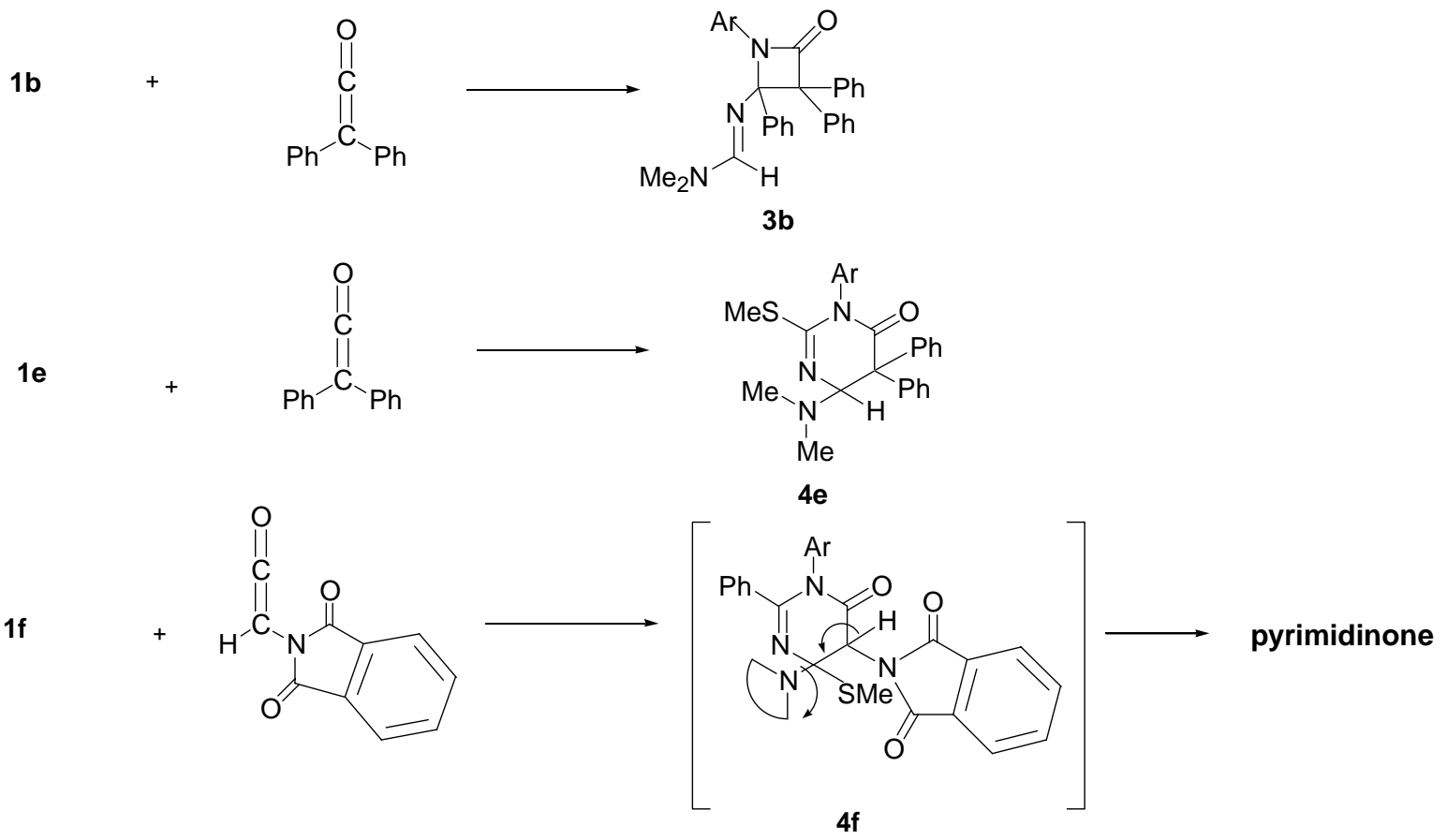

\section{Scheme 2}

It is striking to note that the severe steric interaction expected due to the proximity of four phenyl groups was also not inhibitive for the formation of pyrimidinone $\mathbf{5 b}$. In continuation of the present investigations, it was felt that the reactions of 2-methylthio-substituted 1,3-diazabuta1,3-dienes having $\mathrm{N}-1$ benzyl, instead of a phenyl, with ketenes may result in the isolation of [2+2] cycloadducts due possibly to the reduced steric interaction between N-1 benzyl and C-4 substituents. Accordingly, the reactions of $\mathbf{1 1}$ with monophenyl and diphenylketenes have been examined and interestingly, these reactions also resulted in the exclusive formation of [4+2] cycloadducts $\mathbf{7 a}$ and $\mathbf{7 b}$ respectively, instead of azetidinones $\mathbf{8 a}$ and $\mathbf{8 b}$ expected on steric grounds (Scheme 3). These cycloadducts were assigned the structures $\mathbf{7 a}$ and $\mathbf{7 b}$ with the help of spectral evidences. The formation of pyrimidinones $\mathbf{6}$ and $\mathbf{7}$ in these reactions are clearly at odds 
with steric arguments advanced by Rossi and coworkers ${ }^{5 \mathrm{~d}}$ and by Wurthwein et al. ${ }^{5 \mathrm{~b}}$ The $[4+2]$ cycloaddition pathway followed in these reactions is not exclusively controlled by the steric factors and the observed difference in reactivity of C-2 phenyl and C-2 methylthio substituted 1,3-diazabuta-1,3-dienes with ketenes may probably be due to the difference in their conformational preferences, which in turn depend on the varied electronic influence of the substituents at various positions of the diazadienes.

To support the arguments presented above, $a b$ initio $^{8 \mathrm{a}}$ and density functional studies (DFT

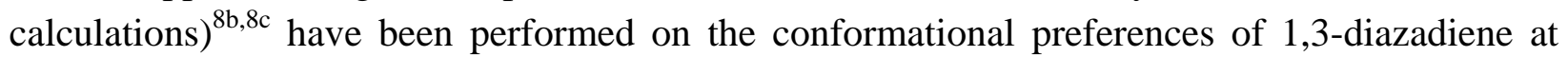
HF/6-21, MP2/6-31G*, MP2/6-31+//HF/6-31+G*, B3LYP/6-31+G**//B3LYP/6-31G* levels using Gaussian 94W series of programs. Absolute energies and relative energies on including ZPE corrections ${ }^{9}$ reveal that s-cisoid is the preferred conformation on the $\mathbf{P E}$ surface of $\mathbf{E}$-isomer and s-trans is the preferred conformation on the $\mathbf{P E}$ surface of $\mathbf{Z}$-isomer. ${ }^{10 a}$ (Figure 1)

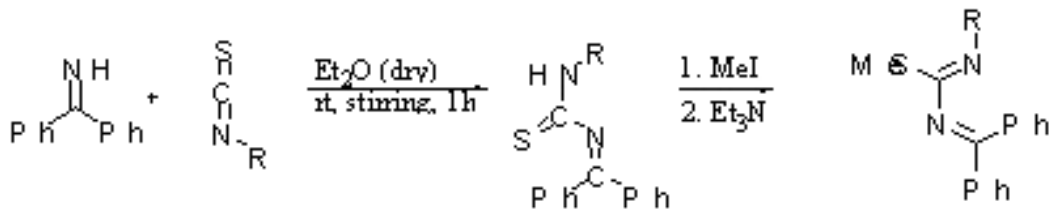

$\mathbf{R}=\mathbf{P h} \mathbf{h} \mathbf{x}$

l.k. $\begin{array}{r}\mathbf{R}=\mathbf{P h} \\ \text { l. } \mathbf{R}=\mathbf{B r}\end{array}$

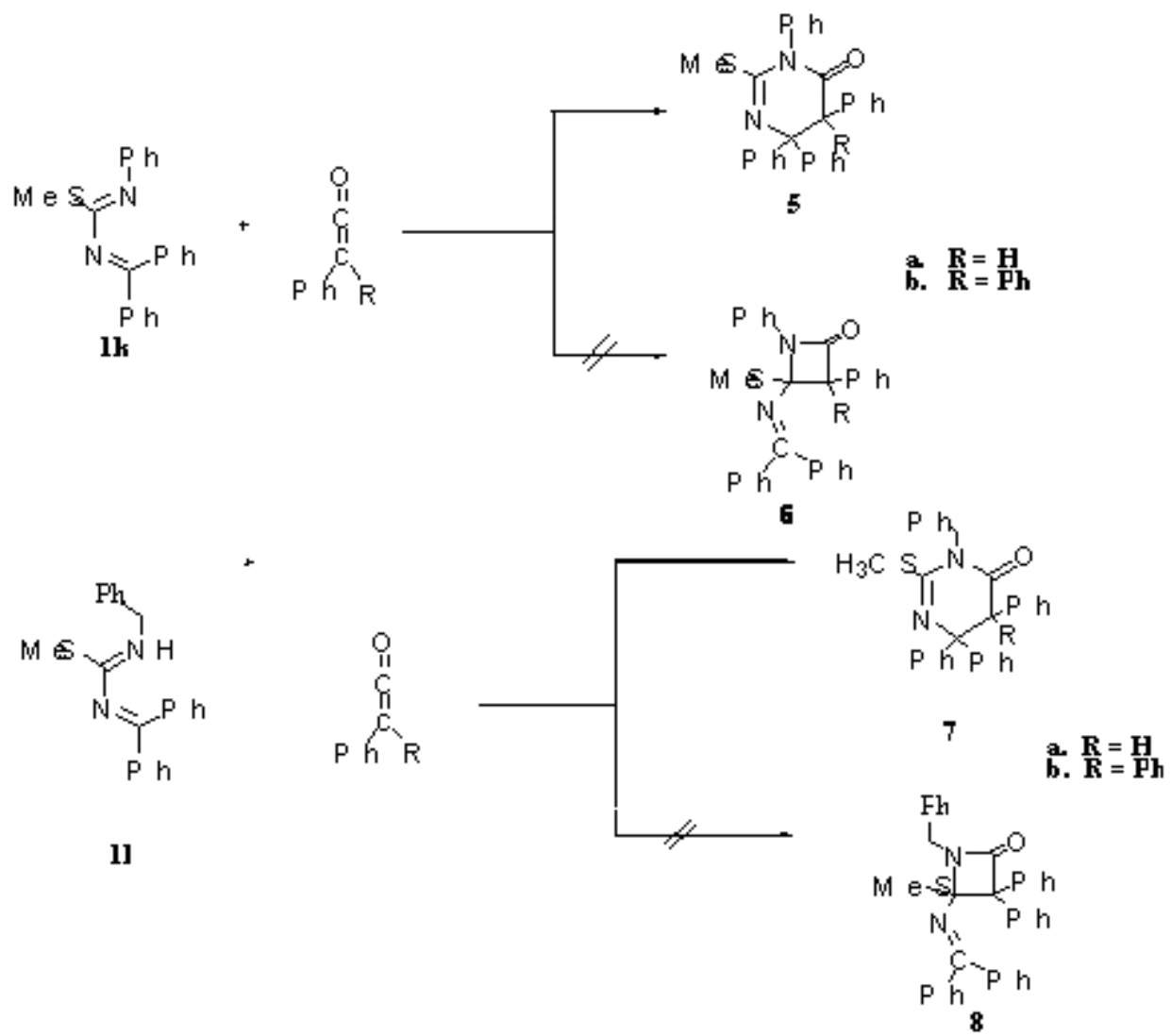

\section{Scheme 3}




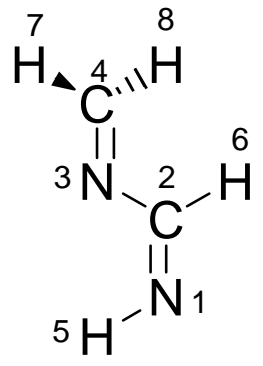

$1 Z$ S-trans

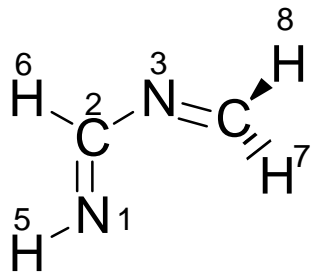

1E S-cisoid

\section{Figure 1}

The presence of hyperconjugatively polar donating groups $\left(\mathrm{NH}_{2}, \mathrm{SH}, \mathrm{Me}\right)$ at $\mathrm{C}-2$ position of 1,3-diazadiene have been found to strongly destabilize s-trans arrangement and increase the propensity of s-cisoid conformation both in gas phase as well as in solvent media. ${ }^{10 a}$ However, the preference for $\mathbf{E}$-cisoid geometry has been observed to diminish under solvent conditions due to relatively less pronounced electron delocalisations in solvents. On the basis of the optimized structures of the transition states observed on the PE surface at various theory levels, it has been deduced that 1E s-cisoid 1,3-diazabuta-1,3-diene-ketene cycloaddition reaction proceed through asynchronously concerted Diels-Alder type pathway leading to the formation of pyrimidinone, whereas the formation of [2+2] cycloadduct, azetidinone originates from the $\mathbf{1 Z}$ s-trans $1,3-$ diazabuta-1,3-diene-ketene cycloaddition. ${ }^{10 \mathrm{~b}}$

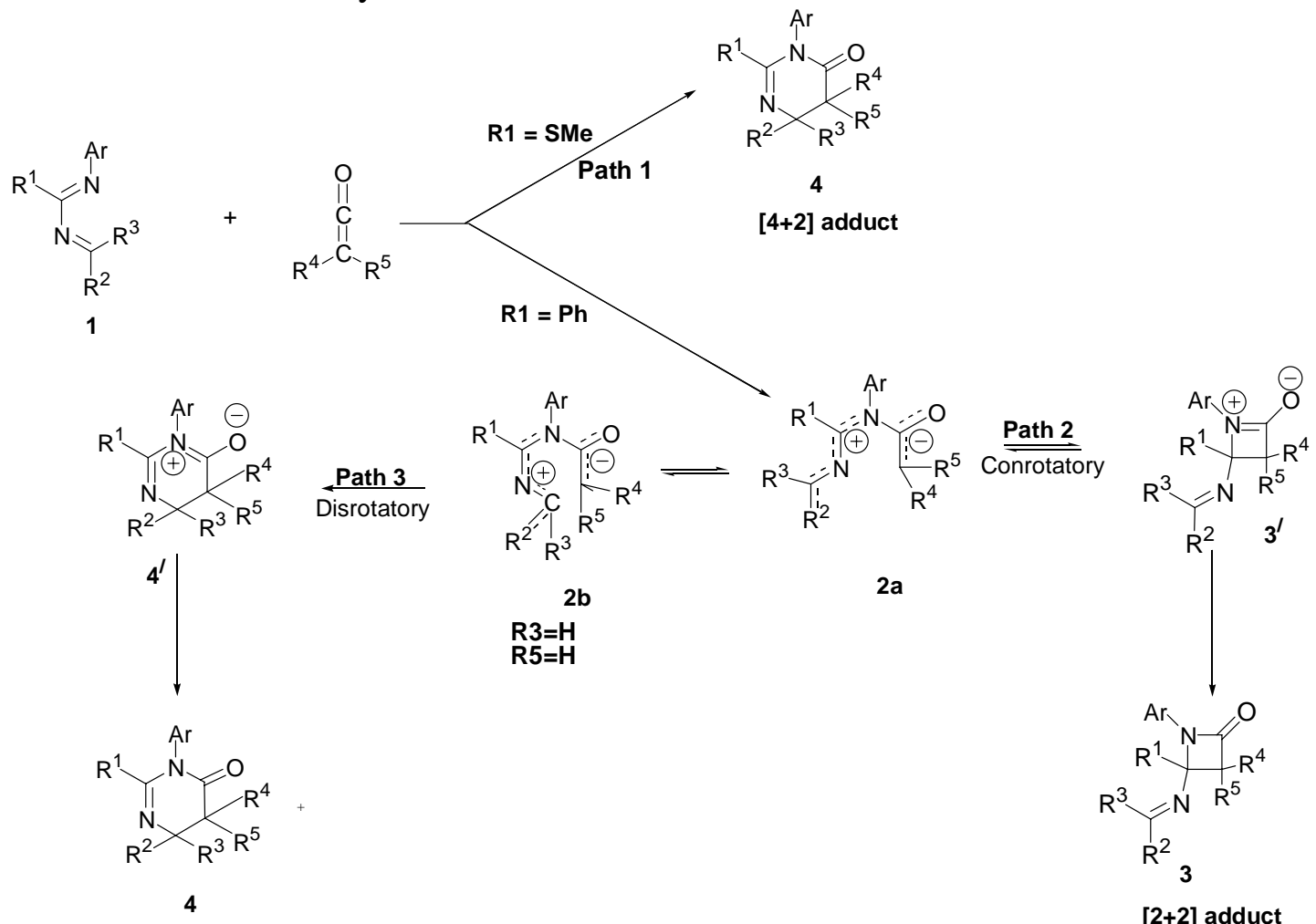

\section{Scheme 4}


The experimental observations supported by theoretical studies blatantly reflect that the reactions of C-2-methylthio substituted 1,3-diazabuta-1,3-dienes with ketenes proceed stereoselectively through asynchronously concerted Diels-Alder type cycloaddition (path 1). The possibility of the initial formation of [2+2] cycloadduct could be ruled out, as it is less likely for the sterically less demanding [2+2] cycloadducts to transform to sterically more crowded [4+2] cycloadducts. On the other hand, the reactions of C-2 phenyl substituted 1,3-diazabuta-1,3dienes with ketenes proceed through the initial formation of zwitterionic intermediate which exists in two interconvertible forms $\mathbf{2 a}$ and $\mathbf{2 b}$ due to smaller barrier across C-N bond (Scheme 4). The conrotatory ring closure (path 2) of the intermediate 2 a results in azetidinone 3 as isolable products provided the substituents at $\mathrm{N}-1, \mathrm{C}-3$ and $\mathrm{C}-4$ do not impose severe steric constraints. In case of demanding steric constrictions between these substituents, azetidinone $\mathbf{3}$ opens up to the sterically less demanding intermediate $\mathbf{2 b}$ via $\mathbf{2 a}$ which undergoes disrotatory ring closure (path 3) to stereoselectively form pyrimidinone 4 . The above arguements also reasonably explain the till date dubious query about the remarkable stereoselectivity observed in the formation of pyrimidinones in 1,3-diazabuta-1,3-diene-ketene cycloadditions involving a zwitterionic intermediate. Thus, the conformational preferences of 1,3-diazabuta-1,3-dienes appear to be discernible in controlling the cycloaddition reaction pathways between 1,3diazabuta-1,3-dienes with ketenes.

\section{Experimental Section}

General Procedures. Melting points were determined by open capillary method using Veego Precision Digital Melting Point apparatus (MP-D) and are uncorrected. IR spectra were recorded on a Shimadzu D-8001 spectrophotometer. ${ }^{1} \mathrm{H}$ NMR were recorded in deuteriochloroform with Brucker AC-E 200 (200 MHz) spectrometer using TMS as an internal standard. Chemical shifts are expressed as $\delta$-(ppm) downfield from TMS and $J$ values are in $\mathrm{Hz} .{ }^{13} \mathrm{C}$ NMR spectra were also recorded on a Brucker AC-E 200 (50.4 MHz) spectrometer in deuteriochloroform using TMS as an internal standard. Mass spectra were recorded on SHIMADZU GCMS-QP-2000 mass spectrometer.

Starting materials. Phenyl/benzyl isothiocyanate ${ }^{11}$ and diphenylmethanimine ${ }^{12}$ were prepared by the following reported procedures.

1-Phenyl/benzyl-4,4-diphenyl-2-methylthio-1,3-diazabuta-1,3-diene (1k and 1l). To a wellstirred solution of phenyl or benzylisothiocyanate $(5.5 \mathrm{mmol})$ in dry diethylether $(10 \mathrm{ml})$ was added diphenylmethanimine $(5.5 \mathrm{mmol})$ and the mixture strirred at room temperature for $1-2 \mathrm{~h}$ until tlc confirmed the formation of the product. A solution of thioamide $(2.5 \mathrm{mmol})$ so obtained and methyl iodide $(2.7 \mathrm{mmol})$ in dry acetone $(20 \mathrm{ml})$ was further stirred at room temperature for $1.5 \mathrm{~h}$. The hydroiodide salt so obtained was basified using triethylamine $(2.7 \mathrm{mmol})$, washed 
with water $(2 \times 10 \mathrm{ml})$, extracted with dichloromethane and the organic layer dried over anhydrous sodium sulphate. The solvent was then removed under reduced pressure and the crude product was recrystallized from a mixture (1:2) of chloroform and hexane.

1,4,4-Triphenyl-2-methylthio-1,3-diazabuta-1,3-diene (1k). Yellowish crystalline solid (chloroform/hexane); Yield 89\%; m.p. 148-149 ${ }^{\circ}$ C; (Found: C, 76.23; H, 5.40; N, 8.32; S, 10.05; $\mathrm{C}_{21} \mathrm{H}_{18} \mathrm{~N}_{2} \mathrm{~S}$ requires C, 76.36; H, 5.45; N, 8.48; S, 9.7): $v_{\max }(\mathrm{KBr}): 1637 \mathrm{~cm}^{-1}(-\mathrm{C}=\mathrm{N}) ;{ }^{1} \mathrm{H} \mathrm{NMR}$ $\left(\mathrm{CDCl}_{3}, \delta\right.$ ppm from TMS): 2.40 (s, 3H, -SMe); 6.51-7.47 (m, 15H, arom); ${ }^{13} \mathrm{C} \mathrm{NMR}\left(\mathrm{CDCl}_{3}\right)$ : 15.7 (-SMe), 127.1, 127.5, 127.9, 128.4, 128.7, 129.0, 130.3, 130.7, (CH, arom), 142.5-142.9 ($\mathrm{C}=\mathrm{N}) \cdot \mathrm{M}^{+}: 330$.

1-Benzyl-2-methylthio-4,4-diphenyl-1,3-diazabuta-1,3-diene (11). Yellowish solid (chloroform/hexane); Yield, 88\%; m.p. 87-88 ${ }^{\circ}$ C; (Found: C, 76.49; H, 5.96; N, 8.19; S, 9.36; $\mathrm{C}_{22} \mathrm{H}_{20} \mathrm{~N}_{2} \mathrm{~S}$ requires $\mathrm{C}$, 76.74; $\left.\mathrm{H}, 5.81 ; \mathrm{N}, 8.14 ; \mathrm{S}, 9.30\right) ; v_{\max }(\mathrm{KBr}): 1643 \mathrm{~cm}^{-1}(-\mathrm{C}=\mathrm{N}) ;{ }^{1} \mathrm{H}$ NMR (CDCl 3 , $\delta$ ppm from TMS): 2.28 (s, 3H, -SMe); 4.43 (s, 2H, - $\mathrm{CH}_{2^{-}}$); 6.89-7.44 (m, 15H, arom); ${ }^{13} \mathrm{C}$ NMR $\left(\mathrm{CDCl}_{3}\right): 15.9$ (-SMe), $53.6\left(-\mathrm{CH}_{2}\right), 126.3,127.6,127.8,128.1,128.2,129.1$, 130.8 (CH, arom), 141.1, $141.4(-\mathrm{C}=\mathrm{N}) . \mathrm{M}^{+}: 344$.

\section{Reactions of 1,3-diazabuta-1,3-dienes (1k and 1l) with ketene. General procedure}

To a well-stirred solution of 1,3-diazabuta-1,3-dienes (4 mmol) and dry triethylamine (1.4 ml, 10 $\mathrm{mmol})$ in dry dichloromethane $(30 \mathrm{ml})$, was added dropwise a solution of phenylacetyl chloride $(6 \mathrm{mmol})$ in dry dichloromethane $(30 \mathrm{ml})$ over a period of $1 \mathrm{~h}$. The mixture was further stirred at room temperature for a period of about $2 \mathrm{hr}$ till the completion of the reaction (tlc). The reaction mixture was then washed with water $(3 \times 20 \mathrm{ml})$ and sodium bicarbonate solution $(2 \times 20 \mathrm{ml})$ and finally dried over anhydrous sodium sulphate. Removal of the solvent under reduced pressure yielded crude product which was purified through silica gel column chromatography and recrystallized from a mixture (1:2) of chloroform and hexane.

3,5,6,6-Tetraphenyl-2-methylthio-3,4,5,6-tetrahydropyrimidin-4-one (5a). White solid (chloroform/hexane): Yield, 82\%; m.p. 185-186º C; (Found: C, 77.76; H, 5.30; N, 6.30; O, 3.53; $\mathrm{S}$, 7.11; $\mathrm{C}_{29} \mathrm{H}_{24} \mathrm{~N}_{2} \mathrm{OS}$ requires $\mathrm{C}$, 77.68; H, 5.36; N, 6.25; O, 3.57; S, 7.14). $v_{\max }(\mathrm{KBr}): 1707$ ($\mathrm{C}=\mathrm{O}) .{ }^{1} \mathrm{H}$ NMR $\left(\mathrm{CDCl}_{3} \delta \mathrm{ppm}\right.$ from TMS) : 2.57 (s, 3H, -SMe); 4.79 (s, 1H, methine); 6.987.56 (m, 20H, arom). ${ }^{13} \mathrm{C}$ NMR $\left(\mathrm{CDCl}_{3}\right)$ : 15.2 (-SMe), 55.47 (Ph-CH-C=O), $66.4\left(\mathrm{Ph}_{2}-\mathrm{C}-\mathrm{N}\right)$, 126.2, 126.7, 127.0, 127.1, 127.5, 128.1, 128.2, 128.6, 129.0, 129.3 (CH, arom), 134.3, 135.3, 144.3, 145.7 (C, arom), $155.1(-\mathrm{C}=\mathrm{N}), 168.7$ (-C=O). $\mathrm{M}^{+}: 448$.

3,5,5,6,6-Pentaphenyl-2-methylthio-3,4,5,6-tetrahydropyrimidin-4-one (5b). White solid (chloroform/pet. ether): Yield, 90\%; m.p. 198-199 ${ }^{\circ} \mathrm{C}$ (Found: C, 80.02; H, 5.22; N, 5.26; O, 3.10; S, $6.40 \mathrm{C}_{35} \mathrm{H}_{28} \mathrm{~N}_{2} \mathrm{OS}$ requires C, 80.15; H, 5.34; N, 5.34; O, 3.05; S, 6.11). $v_{\max }(\mathrm{KBr})$ : $1708 \mathrm{~cm}^{-1}(-\mathrm{C}=\mathrm{O}) .{ }^{1} \mathrm{H}$ NMR $\left(\mathrm{CDCl}_{3}, \delta \mathrm{ppm}\right.$ from TMS) : 2.43 (s, 3H, -SMe); 6.83-7.83 (m, 25H, arom). ${ }^{13} \mathrm{C}$ NMR $\left(\mathrm{CDCl}_{3}\right): 15.3$ (-SMe), $61.4\left(\mathrm{Ph}_{2} \mathrm{C}-\mathrm{C}=\mathrm{O}\right), 72.7\left(\mathrm{Ph}_{2} \mathrm{C}-\mathrm{N}\right)$, 125.5, 126.6, 127.3, 128.3, 129.0, 129.2 (CH, arom), 130.2, 131.9, 135.9, 136.3, 139.0 (C, arom), $152.7(-\mathrm{C}=\mathrm{N})$, $173.0(-\mathrm{C}=\mathrm{O}) . \mathrm{M}^{+}: 448$. 
3-Benzyl-5,6,6-triphenyl-2-methylthio-3,4,5,6-tetrahydropyrimidin-4-one (7a). White solid (chloroform/hexane); Yield, 82\%.; m.p. 186-188 ${ }^{\circ}$ C; (Found: 77.69; H, 5.62; N, 6.09; O, 3.50; S, $7.1 \mathrm{C}_{30} \mathrm{H}_{26} \mathrm{~N}_{2} \mathrm{OS}$ requires $\mathrm{C}$, 77.92; H, 5.63; N, 6.06; O, 3.46; S, 6.92). v max $(\mathrm{KBr}): 1703 \mathrm{~cm}^{-1}(-$ $\mathrm{C}=\mathrm{O}) .{ }^{1} \mathrm{H}$ NMR $\left(\mathrm{CDCl}_{3} \delta \mathrm{ppm}\right.$ from TMS): 2.64 (s, 3H, -SMe), 4.81 (s, 1H, methine), 5.33 (s, 2H, -Ph-CH-C=O), 6.89-7.49 (m, 20H, arom). ${ }^{13} \mathrm{C} \mathrm{NMR}\left(\mathrm{CDCl}_{3}\right)$ : 15.1 (-SMe), 45.3 (Ph-CH-), 55.3, $67.7\left(\mathrm{Ph}_{2} \mathrm{C}-\mathrm{N}\right), 126.3,126.7,126.9,127.0,127.3,127.7,128.1,128 ., 128.5,129.3(\mathrm{CH}$, arom), 136.4, 144.5, $154.6(\mathrm{C}=\mathrm{N}), 169.2(-\mathrm{C}=\mathrm{O}) . \mathrm{M}^{+}: 462$.

3-Benzyl-5,5,6,6-tetraphenyl-2-methylthio-3,4,5,6-tetrahydropyrimidin-4-one (7b). White solid (benzene/hexane); Yield, 91\%; m.p. 192-194 C (Found: C, 80.17; H, 5.62; N, 5.11; O, 3.05; S, 6.05; $\mathrm{C}_{36} \mathrm{H}_{30} \mathrm{~N}_{2} \mathrm{OS}$ requires $\mathrm{C}$, 80.29; H, 5.58; N, 5.20; O, 2.97; S, 5.95). $v_{\max }(\mathrm{KBr})$ : $1703 \mathrm{~cm}^{-1}(-\mathrm{C}=\mathrm{O}) .{ }^{1} \mathrm{H}$ NMR $\left(\mathrm{CDCl}_{3}, \delta \mathrm{ppm}\right.$ from TMS) : 2.52 (s, 3H, -SMe); 4.92 (s, 2H, -CH2); 6.67-7.23 (m, 25H, arom); ${ }^{13} \mathrm{C}$ NMR $\left(\mathrm{CDCl}_{3}\right): 15.3$ (-SMe), $47.4\left(-\mathrm{CH}_{2}\right), 66.9\left(\mathrm{Ph}_{2}-\mathrm{C}-\mathrm{N}\right), 72.3$ $\left(\mathrm{Ph}_{2} \mathrm{C}-\mathrm{C}=\mathrm{O}\right), 125.5,127.2,128.1,128.2,130.0$ (CH, arom), 132.1, 134.9, 136.0 (C, arom), 152.3 $(-\mathrm{C}=\mathrm{N}), 170.9(-\mathrm{C}=\mathrm{O}) . \mathrm{M}^{+}: 538$.

\section{Acknowledgements}

The authors gratefully acknowledge the financial support by CSIR, New Delhi, under grant No: 01(1590/99/EMR-11) and the valuable assistance from Dr. P. V. Bharatam in computational work is greatly acknowledged.

\section{References}

1. (a) Valenti, E.; Pericas, M.A.; Mayana, A. J. Org. Chem. 1990, 55, 3582. (b) Wang, X.; Houk, K. N. J. Org. Chem. 1990, 112, 1754. (c) Yambe, S.; Minato, T.; Osamura, Y. J. Am. Soc. 1993, 450. (d) Bernadi, F.; Bottoni, A.; Robb, M. A.; Venturini, A. J. Am. Chem. Soc. 1990, 112, 2106.

2. (a) Lynch, J. E.; Riseman, S. M.; Laswell, W. L.; Tschaen, D. M.; Volante, R. P.; Smith, G. B.; Shinkay, I. J. Org. Chem. 1989, 54, 3792. (b) Cossio, F. P.; Ugalde, J. M.; Lopez, X.; Lecea, B.; Palomo, C. J. Am. Chem. Soc. 1993, 115, 995. (c) Lopez, R.; Sordo, J. A.; Gonzalez, J. J. Org. Chem. 1993, 58, 7036. (d) Cossio, F. P.; Arrieta, A.; Lecea, B.; Ugalde, J. M. J. Am. Chem. Soc. 1994, 116, 2085. (e) Arrieta, A.; Ugalde, J. M.; Cossio, F. P.; Lecea, B. Tetrahedron Lett. 1994, 35, 4465. (f) Arrieta, A.; Lecea, B.; Cossio, F. P. J. Org. Chem. 1998, 63, 5869. (g) Staudinger, M. Liebigs. Ann. Chem. 1907, 356, 51.

3. (a) Tidwell, T. T. Ketenes, Wiley: New York, 1995. (b) Tidwell, T. T. Acc. Chem. Res. 1990, 23, 273. (c) Hyatt, J. A.; Raynolds, P. W. Org. React. 1994, 45, 159. (c) Huisgen, R.; Otto, P., Tetrahedron Lett. 1968, 43, 4491. (d) Huisgen, R.; Otto, P. Chem. Ber. 1969, 102, 3475. (d) The Chemistry of Ketenes, Allenes and Related Compounds. In The Chemistry of 
Functional Groups; Patai, S. Ed.; Wiley: Chichester, U.K., 1980; Parts 1 and 2. (e) Bellus, D.; Ernst, B. Angew. Chem., Int. Ed. 1988, 27, 797 and the references cited therein. (f) Jayakumar, S.; Ishar, M. P. S.; Mahajan, M. P. Tetrahedron 2002, 58, 379.

4. (a) Durckheimer, W.; Blumback, J.; Lattrell, R.; Sheunemann, K. H. Angew. Chem., Int. Ed. 1985, 24, 180. (b) Brady, W. T.; Gu, Y. J. Org. Chem. 1989, 54, 2834. (c) Alcaide, B.; Camtalego, Y. M.; Plumet ,J.; Lopez, J. R.; Sierra, M. A. Tetrahedron Lett. 1991, 32, 803.

5. (a) Matsuda, I.; Yamamoto, S.; Ishii, Y. J. Chem. Soc., Perkin Trans 1, 1976, 1523. (b) Luthardt, P.; Wurthwein, E.-U. Tetrahedron Lett. 1988, 29, 921. (c) Luthardt, P.; Moller, M. H.; Rodewald, U.; Wurthwein, E.-U. Chem. Ber. 1989, 122, 1705. (d) Rossi, E.; Abbiatti, G.; Pini, E. Tetrahedron 1997, 53, 14107.

6. (a) Mazumdar, S. N.; Ibnusaud, I.; Mahajan, M. P. Tetrahedron Lett. 1986, 27, 5875. (b) Mazumdar, S. N.; Mahajan, M. P. Tetrahedron 1991, 47, 1473. (c) Mazumdar, S. N.; Mukherjee, S.; Sharma, A. K.; Sengupta, D.; Mahajan, M. P. Tetrahedron 1994, 50, 7579. (d) Mukherjee, S.; Mazumdar S. N.; Sharma, A. K.; Mahajan, M. P. Heterocycles 1998, 47, 933. (e) Dey, P. D.; Sharma, A. K.; Bharatam, P. V.; Mahajan, M. P. Tetrahedron 1997, 53, 13829. (f) Mazumdar, S. N.; Mahajan, M. P. Synthesis 1990, 417. (g) Sharma, A. K.; Mahajan, M. P. Heterocycles 1995, 40, 787. (h) Dey, P. D.; Sharma, A. K.; Rai, S. N.; Mahajan, M. P. Tetrahedron 1995, 51, 7459.

7. Kumar, R. Senthil, Ph.D Thesis, Dept. of Pharmaceutical Sciences, Guru Nanak Dev University, Amritsar, submitted.

8. (a) Hehre, W. J.; Radom, L.; Schleyer, P. v. R.; Pople, J. A. Ab initio Molecular Orbital Theory, Wiley-Interscience: New York, 1986. (b) Foresman, J. B.; Frisch, E. Exploring Chemistry with Electronic Structure Methods 2nd Edn. Gaussian Inc. Pittsburgh. (c) Bartolotti, L. J.; Fluchick, K. In Reviews in Computational Chemistry; Lipkowitz, K. B.; Boyd, D. B.; Eds.; VCH Publishers: New York, 1996; Vol. 7, pp 187-216. (d) Pare, R. G.; Yang, W. Density Functional Theory of Atoms and Molecules; Oxford: New York, 1989.

9. (a) Reed, A. E.; Weinstock, R. B.; Weinhold, F. J. Chem. Phys. 1985, 83, 735. (b) Reed, A. E.; Curtiss, L. A.; Weinhold, F. Chem. Rev. 1988, 88, 899.

10. (a) Marwaha, A.; Kumar, R. S.; Bharatam, P. V.; Mahajan, M. P. Theochem (Accepted). (b) Bharatam, P. V.; Kumar, R. S.; Mahajan, M. P. Org. Lett. 2000, 2, 2725 and the references cited therein.

11. Vogel's Textbook of Practical Organic Chemistry; Furness, Hannaford, Smith, Tatchell; $5^{\text {th }}$ Edn.; Longman Singapore Publishers Pte. Ltd.

12. Stevens, C. L.; French, J. C. J. Am. Chem. Soc. 1953, 75, 657. 